И.А. Шидловская (доц. ОГУ, г. Оренбург)

\title{
ОСОБЕННОСТИ ПЕРЕВОДА ДЕТСКОЙ ХУДОЖЕСТВЕННОЙ ЛИТЕРАТУРЫ С НЕМЕЦКОГО ЯЗЫКА НА РУССКИЙ (НА МАТЕРИАЛЕ ПОВЕСТИ Э. КЕСТНЕРА «МАЛЬЧИК ИЗ СПИЧЕЧНОЙ КОРОБКИ»)
}

В статье рассматриваются способы перевода детской художественной литературы с немеикого языка на русский. Автор рассуждает об особой функиии произведений для детей, которая призвана воспитывать основы морали $u$ нравственности подрастающего поколения в поликультурном пространстве. В статье выявлены и проанализированы способы перевода произведения, при помощи которых переводчик отобразил замысел, задуманный автором оригинала.

Ключевые слова: детская художественная литература, воспитательная функция, переводческие трансформации, эквивалентность перевода, адекватность перевода, средства выразительности.

The article discusses the ways of translating children's fiction from German into Russian. The author discusses the special function of works for children, which is designed to educate the foundations of morality and morality of the younger generation in a multicultural space. The article identifies and analyzes the methods of translation of the work, with the help of which the translator displayed the idea conceived by the author of the original.

Keywords: children's fiction, educational function, translation transformations, translation equivalence, translation adequacy, means of expression.

Детская литература как огромный пласт художественной литературы призвана формировать у подрастающего поколения, в первую очередь, правильное нравственное восприятие окружающей действительности. Принцип развития у детей навыков, умений и талантов лежит в основе как отечественной 
детской литературы, так и зарубежной, особенно в фольклорном творчестве [Архипов 2017: 2].

Как известно, детский фольклор многих зарубежных стран является художественной мировой классикой. Данному факту, безусловно, способствуют переводчики, которые передают народной язык весь национальный колорит произведения, учитывая при этом ментальность родной страны. Самыми известными приводчиками в нашей стране являются К.И. Чуковский и С.Я. Маршак. Благодаря им английские, а также шотландские баллады не только не утратили своей национальной специфики, но и кажутся русскоязычному читателю настоящими русскими оригинальными стихами [Бархударов 2013].

Если речь идет о детской зарубежной литературе, то в нашей стране превалируют англоязычные произведения. При опросе как детей, так и взрослых, относительно немецких детских писателей, были названы лишь братья Гримм и их сказки. Справедливости ради, хотелось бы отметить, что немецкая детская литература в силу различных политических причин, долгое время действительно находилась в состоянии стагнации. Тем значительнее становится вклад знаменитого немецкого детского писателя Э. Кестнера в формировании основ морали и нравственности поколения 20-21в. Особую популярность в нашей стране получили такие его книги как «Эмиль и сыщики», «Двойная Лоттхен», «Летающий класс» и др. Этой популярности способствовали, в первую очередь, переводчики, которые сумели передать максимально возможный равноценный текст на языке перевода и максимально достоверно передать все эмоции и чувства автора произведения. Для маленького ребёнка особенно очень важно его отношение к литературным персонажам, а также к их переживаниям, чувствам и поступкам. Такие отношения ко всем героям произведений для детей создается у юных читателей благодаря образу, который пытается создать автор произведения, а затем передать и переводчик.

На примере повести-сказки Э. Кестнера «Мальчик из спичечной коробки» мы проанализировали те средства, посредством которых переводчик К. Богатырев передал весь замысел автора. При исследовании этого произведения было выявлено множество переводческих трансформаций, при помощи которых русскоязычное пространство узнало увлекательную 
историю о приключениях маленького Максика и его приемного отца фокусника Йокуса фон Покуса.

Уже с перевода названия, мы сталкиваемся с контекстуальной заменой или окказиональным соответствием. Оригинальное название Der kleine Mann. Маленький мужчина было заменено на Мальчик из спичечной коробки с целью погружения маленьких читателей в мир сказки. Переводчик использовал этот нерегулярный прием для того, чтобы кратко описать главного героя и его первоначальный дом.

Имена собственные были переданы при помощи транскрибирования:

Wu Fu und Tschin Tschin / Geburtsort: Stockholm. Ву Фу и Чин Чин. Место рождения - Стокгольм.

Professor Jokus von Pokus hält eine schöne Rede. Профeccop Йокус фон Покус держит речь.

Oder im Speisesaal des Hotels Excelsior in Amsterdam? Или в ресторане гостиницы «Эксиельсиор» в Амстердаме?

В следующем примере переводчик использовал прием транслитерации, поскольку и в названии самой деревушки и ее жителей происходит традиционная замена немецкого дифтонга ei- на русский -ей-: Pichelstein und die Pichelsteiner. Пихельштейн и Пихельштейнеры. Указание на множественность посредством транслитерации мы находим при переводе фамилии Bambus, a именно Бамбусы, семья Бамбусов, которое звучит более привычно для русского читателя.

Согласно классификации В.Н. Комиссарова, которой мы придерживаемся в данной статье, конкретизация представляет собой замену некоторых слов или даже словосочетаний на исходном иностранном языке. Такие конкретизации обычно имеют куда более широкое предметное и логическое значение и заменяются на такие слова и словосочетания на языке перевода, к которые имеют более узкое значение [Комиссаров 2012]:

Dort gibt es einen hohen Berg und ein kleines Dorf, und beide heißen Pichelstein.

Там есть высокая гора, а под нею - маленькая деревушка, и все это зовется Пихельштейн.

В оригинальном варианте автор не упоминает соотношение расположения горы и деревушки. Переводчик же решил уточнить, что деревушка находится под горой. Этот прием 
помогает читателю красочнее представить пейзаж и осознать превосходство горы над всей деревней, включая её маленьких жителей.

«Anstelle der Streichhölzer, die üblicherweise drinliegen, enthielt sie ein Maträtzchen aus Watte ... und ein Kopfkissen, nicht größer als der Nagel meines Mittelfingers.»

Вместо шестидесяти спичек в ней помещались ватный тюфячок, ...подушка размером с ноготь на моём безымянном пальце и сам Максик.

Перевод включает упоминание о количестве спичек, находящихся в одной спичечной коробке. Возможно предположить, что таким образом, переводчик конкретизирует размер коробочки и дает больше возможностей читателю представить рост и вес Максика.

Прием генерализации как способа перевода, преобразовывающий определенную единицу исходного языка, которая имеет более узкое значение, на единицу переводящего языка, которая имеет более широкое значение [Комиссаров 2012], отчетливо прослеживается в следующем примере:

Eines steht jedenfalls fest: Mäxchens Eltern und Großeltern und Urgroßeltern und sogar die Urururgroßeltern stammten aus dem Böhmerwald.

Но уж одно-то я знаю твёрдо: и родители Максика, и его бабушки с дедушками, и абсолютно все его предки были родом из Богемского леса.

Оригинальная фраза Urgroßeltern und sogar die Urururgroßeltern была опущены заменена фразой «абсолютно все его предки», что говорит о нечастом использовании в русском языке таких слов, как «прадедушка» и «прабабушка», и тем более слов «прапрадедушка» и «прапрабабушка».

Модуляция, т.е. семантическое (смысловое) развитие, была использована в выражении: Ich glaube, mein Gedächtnis lässt nach. Schade. Проклятая память!

Словарным соответствием глагола «nachlassen» является слово «ухудшаться», а наречия «schade» - «досадно». Можно представить, каким бы тяжеловесным для понимания стал перевод данного отрезка речи, если бы переводчик перевел его дословно. 
«Erst ein Vierteljahr später wurden sie der chinesischen Akrobatentruppe ,Familie Bambus' zugeteilt.»

Только через три месяща их включили в китайскую акробатическую труппу «Семья Бамбусов».

Каждому читателю будет понятен и вариант, предложенный автором повести «Vierteljahr», что дословноо переводится «четверть года», и вариант, предложенный переводчиком данной повести «три месяца». Эти варианты являются эквивалентами, хотя в русском языке словосочетание «четверть года» употребляется гораздо реже словосочетаниюу «три месяца», чем и можно объяснить данную замену.

Und zwei Wochen später, als man auf dem Friedhof, in einem Elfenbeinkästchen, die zwei schwarzen Chinesenzöpfchen begrub, ... da wäre Mäxchen vor lauter Kummer am liebsten mitgestorben.

А когда через две недели на кладбище в маленькой шкатулке из слоновой кости хоронили пару чёрных китайских косичек, ... Максику хотелось умереть от горя.

Предложенный автором глагол «mitsterben» состоит из приставки «mit» и глагола «sterben». Благодаря контексту мы знаем, что родители Максика умерли, и становится понятно, что он хотел бы умереть вместе с ними, что передает приставка «mit», которая переводится «с» или «вместе». В переводе же переводчик опустил значение данной приставки, что не исказило перевод и смысл всего предложения.

Und die Schachtel blieb halb geöffnet, weil ja der Junge sonst keine Luft gekriegt hätte.

Коробка оставалась наполовину открытой, а то бы он задохнулся.

Заменой фразы «keine Luft gekriegt hätte» послужила фраза в тексте перевода «а то бы он задохнулся», что является синонимичным по значению и полностью передает смысл, задуманный автором повести.

«Die drei Tiere gehörten dem Professor und halfen ihm, wenn er im Zirkus auftrat.»

Все трое служсли у профессора и помогали ему выступать в цирке.

В данном случае немецкий глагол «gehören» получил более широкое значение, чем обычно. Чаще всего он переводится «принадлежать», но, исходя из контекста, в котором сказано, что 
три животных так же принимали участие в постановках и выступлениях в цирке, а значит, работали там, переводчик использовал значение «служить».

Mit sieben Jahren hatte er natürlich in die Schule gehen wollen.

В семь лет он, конечно, мечтал учиться в школе.

В приведенном примере немецкий модальный глагол «wollen», получает не только более широкое, но и эмоционально более окрашенное значение, чем просто «хотеть», а именно «мечтать». Использование данной переводческой трансформации говорит читателю о том, что переводчик имел цель подчеркнуть сильнейшее желание Максика ходить в школу.

В анализируемой сказочной повести встречается довольно большое количество таких грамматических трансформаций, как синтаксическое уподобление или дословный перевод, при котором синтаксическая структура оригинала преобразуется в аналогичную структуру языка перевода [Комиссаров 2012]:

Professor Jokus von Pokus hält eine schöne Rede.Ipoфeccop Йокус фон Покус держит речь.

Das war, wenn ich mich nicht irre, in London. Это бълло, если не оиибаюсь, в Лондоне.

Denn es war Mittwoch. Потому что бьла среда.

Можно заметить, что дословный перевод чаще всего встречается в коротких предложениях. Такое явление объясняется тем, что длинные, насыщенные различными стилистическими конструкциями предложения невозможно передать на язык перевода, сохранив и грамматическую, и синтаксическую, и семантическую целостность.

Краткость предложений переводчик предпочитает использовать, применяя такую переводческую трансформацию, как членение предложений с целью преобразования синтаксической структуры предложения на языке оригинала в две или более предикативные структуры в языке перевода [Комиссаров 2012]:

Und weil das Dorf Pichelstein im Böhmerwald für ihre Pläne und Wünsche nicht ausreichte, fuhr das Ehepärchen mit Sack und Pack, nein, mit Säckchen und Päckchen, in die weite Welt hinaus. 
...их плань не умещались в деревушке Пихельштейн в Богемском лесу. И вот в один прекрасный день супруги захватили своипожитки, а вернее пожсточкии, иотправились в далёкий путь.

Die Tauben hockten oben auf dem Schrank, sie hatten die Köpfe in die Brustfedern gesteckt, und wenn sie träumten, gurnten sie.

Голуби спали на иккафу. Они зарывались головками в перья и тихонько ворковаливосне.

При анализе исследуемого произведения было установлено превалирование такой переводческой трансформации, как членение предложений. Отчетливо прослеживается тенденция к упрощению предложений и уменышению количества сложноподчиненных и сложносочинённых предложений. Данный факт объясняется тем, что К. Богатырев осуществлял перевод именно детской сказочной повести и перегружать перевод сложными конструкциями было бы нецелесообразно, т.к. дети не воспринимают их должным образом. А цель переводчика передать замысел автора таким образом, чтобы ребенок без особых усилий смог представить в своем воображении образы действующих лиц с их эмоциями и действиями.

В заключении, хотелось бы еще раз подчеркнуп, что перевод детской литературы является одним из наиболее сложных видов перевода, т.к. рассчитан на определенную возрастную категорию. Изначальная цель автора оригинала это воспитание у детей основ морали и нравственности посредством определенных художественных приемов. Задача переводчика передать эти приемы, не исказив задуманного автором смысла. Безусловно, перевод повестисказки Э. Кестнера «Мальчик из спичечной коробки», осуществленный К. Богатыревым, в полной мере не только отобразил атмосферу происходящего, но и способствовал осуществлению воспитательной функции.

\section{ЛИТЕРАТУРА}

1. Архипов ИК. Человеческий фактор в языке // Лексическая, категориальная и функциональная семантика: сб.науч.тр. - МГПИИЯ им. М. Тореза. - М., 2017.-C.3-10.

2. Бархударов Л.С. Языки перевод-M.:URSS., 2013.-240 c.

3. Кестнер Э. Мальчик из спичечной коробки - Издательство: КомпасГ ид, 2019 $176 \mathrm{c}$.

4. Комиссаров В.Н. Современноепереводоведение -М.: ЭТС, 2012.-160 с.

5. Kästner E. Der kleine Mann. - Hueber Verlag, 1987. [Электронный ресурc]. URL: https:/royallib.com/read/stner rich/Der kleine Mann.html\#0 (дата обращения: 14.04.2021).

(С Шидловская И.А., 2021 г. 